\title{
NOTAS INTRODUTÓRIAS SOBRE O PRINCÍPIO DA LIVRE CONCORRÊNCIA
}

\section{INTRODUCTIONS NOTES ABOUT THE PRINCIPLE OF THE FREE COMPETITION}

Carlos Emmanuel Joppert Ragazzo"

\begin{abstract}
Resumo: O presente articulado tem por objetivo trazer algumas reflexões sobre o princípio da livre concorrência. Primeiramente, serão abordados os benefícios de um modelo econômico baseado na livre concorrência e o objetivo tutelado pela mesma, no caso a preservação do processo de competição e não os competidores. Em seguida, serão apresentadas algumas alterações das estruturas de mercado advindas do liberalismo clássico e da livre concorrência, ressaltando os limites à livre iniciativa. Por fim, far-se-á um apanhado histórico da livre concorrência no Brasil, partindo das primeiras legislações acerca da intervenção do estado na economia, que se consubstanciaram em regras contra o abuso do poder e chegando à Constituição Econômica de 1988 e à lei de Defesa da Concorrência (Lei 8884/94), instrumentos imprescindíveis para uma proteção da concorrência mais ampla, o que permite a livre iniciativa atender a sua função social.

Palavras-chave: Livre iniciativa. Livre concorrência. Constituição econômica.
\end{abstract}

Abstract: The articulate present has for objective to bring some reflections on the beginning of the free competition. Firstly, the benefits of an economic model will be approached based on the free competition and the objective tutored by the same, in the case the preservation of the competition process and not the competitors. Soon after, some alterations of the structures of market to get of the classic liberalism will be presented and of the free competition, standing out the limits to the free initiative. Finally, he/she will make himself a caught historical of the free competition

Coordenador Geral de Defesa da Concorrência da Secretaria de Acompanhamento Econômico - Seae/MF. Bacharel pela Pontifícia Universidade Católica do Rio de Janeiro - PUC/RJ. LL.M. in Trade Regulation and Competition Policy (New York University, NYU, 2002). Mestre e Doutorando em Direito pela Faculdade de Direito da Universidade do Estado do Rio de Janeiro (UERJ). Professor dos Cursos de Pós-Graduação em Direito do Estado da UERJ e em Direito Privado Patrimonial da PUC/RJ. 
in Brazil, leaving of the first legislations concerning the intervention of the state in the economy, that if modify in rules against the abuse of the power and arriving to the Economic Constitution of 1988 and the law of Defense of the Competition (Law 8884/94), indispensable instruments for a protection of the widest competition, what allows the free initiative to assist its social function.

Keywords: Free initiative. Free competition. Economic constitution.

\section{INTRODUÇÃO}

A palavra concorrência traz à mente uma série dos mais variados significados. Entre os sinônimos populares, além de refletir a concordância de opiniões, a concorrência pode também expressar o expediente de escolha de um fornecedor de mercadorias ou serviços para entidades governamentais municipais, estaduais ou federais (procedimento licitatório).

No entanto, o significado mais comum (inclusive de acordo com diversos dicionários) é o que reflete a idéia de competição, combate e rivalidade. Essa idéia é a que melhor traduz os primeiros elementos necessários para explicar o princípio da livre concorrência e, em conseqüência, o seu papel no atual modelo constitucional brasileiro.

E justamente com o propósito de explicar o princípio da livre concorrência, este articulado irá delinear os benefícios que resultam de um modelo concorrencial (competitivo), indicando, inclusive, o objetivo final que é por ele tutelado. Após isso, irá descrever brevemente a relação entre o liberalismo e a concorrência, extraindo daí a importância de alguns eventos (como, por exemplo, a revolução industrial), para identificar, em momento posterior, os limites do novo modelo econômico.

Mas não é só. Ultrapassadas as questões preliminares mencionadas acima, descrever-se-á o histórico brasileiro no que se refere à introdução e à permanência dos dispositivos que refletem a aplicação do princípio da livre concorrência. Para tanto, serão analisados dispositivos de constituições passadas, bem como legislações infraconstitucionais que antecederam a Constituição Federal de 1988.

Em conclusão, depois de uma rápida avaliação dos dispositivos constitucionais atualmente em vigor, mais precisamente do Artigo 170, inciso IV e do Artigo 173, parágrafo 4⿳亠丷⿵冂丶 , daquele diploma legal, o presente articulado debaterá alguns aspectos da atual Lei de Defesa da Concorrência (Lei n. 8.884/94). 


\section{A LIVRE CONCORRÊNCIA}

\subsection{Dos Benefícios da Livre Concorrência}

Antes de enveredar por discussões legislativas mais aprofundadas, é necessário descrever os benefícios de um modelo econômico baseado na livre concorrência. Algumas premissas, no entanto, devem ser estabelecidas. A disputa entre concorrentes pela preferência de consumidores em um dado mercado de bens e/ ou de serviços só tem lugar em uma economia de mercado. Não encontra espaço (ou encontra menor espaço) em outros modelos em que o Estado direciona os agentes econômicos privados, ou torna-os secundários, como ocorre, em exemplo derradeiro, no comunismo.

Um Estado extremamente intervencionista não dá oportunidade para que o mercado possa se auto-regular. E, dentro desse contexto, um modelo que garanta a livre concorrência não só se torna ineficaz, mas principalmente sem sentido. As forças de mercado são manipuladas pelo Estado e não atingem os benefícios que tipicamente decorrem de um modelo concorrencial, normalmente regido por agentes econômicos privados.

Retornando à questão dos benefícios, é consenso em diversos países que a economia de mercado com a garantia de livre concorrência é a melhor forma de maximizar o bem-estar social (ou, em termos mais adequados, a eficiência econômica). e isso se dá de diferentes formas. A concorrência aumenta a eficiência alocativa, a eficiência produtiva e a capacidade de inovação dos mercados.

Esses conceitos econômicos têm fácil explicação. A eficiência alocativa se realiza quando bens e/ou serviços são produzidos (em qualidade e quantidade) na medida em que os consumidores os desejam, refletindo, na exata proporção, o preço que eles estão dispostos a pagar (em outras palavras, a alocação de recursos na direção preferida pelos consumidores). Assim, reduz-se a chance de os preços e/ou serviços produzidos não serem de interesse do consumidor.

A eficiência produtiva, por sua vez, diz respeito à capacidade de produzir e de distribuir a custos mais baixos. A pressão contínua decorrente da concorrência dos agentes econômicos competidores incentiva os produtores e distribuidores a reduzirem custos e, conseqüentemente, a praticar preços menores, sob pena de perderem clientes para outros negócios mais eficientes.

Ao lado das eficiências alocativa e produtiva - que por serem aferidas em um dado momento no tempo são consideradas estáticas - o modelo concorrencial também induz maior capacidade de inovação (o que incentiva a competição via diferenciação e oferta de novos produtos). Essa eficiência é considerada dinâmica porque melhora as eficiências alocativa e produtiva no curso do tempo. $\mathrm{O}$ processo 
de adequação às preferências do consumidor representa o incentivo necessário para que os agentes econômicos invistam em pesquisa e tecnologia, de forma a melhorar os seus produtos e serviços. Intuitivamente, aqueles que não tiverem sucesso nessa empreitada perdem espaço.

\subsection{Do Objetivo Tutelado pela Livre Concorrência}

Como explicitado acima, num modelo de livre concorrência há maior variedade de produtos por menores preços, com a criação de incentivos para que as empresas aumentem produtividade e introduzam novas tecnologias. A livre concorrência aumenta o bem estar dos consumidores, ao mesmo tempo em que contribui para o desenvolvimento econômico.

Entretanto, necessariamente do processo de disputa oriundo do modelo concorrencial há vencedores e vencidos. E os efeitos da concorrência se tornam desastrosos para os vencidos, que são obrigados a deixar o mercado, paralisando atividades, em virtude do sucesso de outros agentes econômicos. A concorrência pressupõe um ataque (por meios lícitos, é claro) de um competidor ao outro, seja pela introdução de estratégias de mercado mais eficientes ou mesmo pelo já habitual binômio melhores produtos por menores preços.

Ao contrário do que se pensa, o modelo de livre concorrência não se preocupa necessariamente em manter um grande número de agentes no mercado, como se pode inferir da situação hipotética de concorrência perfeita - comumente considerada como o ideal de livre concorrência - em que há vários compradores e vendedores, todos eles tomadores de preço (incapazes de influenciar preço). Existem estruturas de mercado que são mais eficientes (ou seja, maximizam o bem-estar dos consumidores) com um número menor de agentes econômicos; em casos específicos, a melhor estrutura é o monopólio natural ${ }^{1}$.

Dessa forma, o objetivo da livre concorrência é preservar o processo de competição e não os seus competidores. O processo de competição, no modelo concorrencial, é o que possibilita a repartição ótima dos bens dentro da sociedade, contribuindo para a justiça social. Isso não significa que a concorrência não deve ser sopesada com outros interesses, como, por exemplo, a defesa do meio ambiente, a manutenção de empregos, o desenvolvimento sustentável, entre outros.

${ }^{1}$ Monopólio natural é uma estrutura caracterizada por uma alta escala mínima viável vis-à-vis o tamanho do mercado. Isso se dá em razão dos elevados custos fixos presentes e pelo baixo custo marginal nesse determinado segmento. Em outras palavras, não compensa entrar no mercado porque só há espaço para um agente econômico. 
Embora por vezes excludentes entre si, todos esses interesses devem ser ponderados a fim de que o bem-estar social seja atingido.

\section{O LIBERALISMO CLÁSSICO E A LIVRE CONCORRÊNCIA}

\subsection{Da Alteração das Estruturas de Mercado}

O liberalismo clássico do século XVIII consubstanciava um modelo econômico segundo o qual o Estado era responsável por uma interferência mínima no mercado, sendo apenas um mero garantidor das liberdades individuais. $\mathrm{O}$ direito à propriedade e a autonomia das vontades eram preceitos máximos restringidos apenas quando interferiam na esfera particular de outros indivíduos. Os limites à livre iniciativa eram apenas relacionados à proteção do indivíduo face ao poder estatal.

Dentro desse cenário, a livre concorrência seria apenas uma decorrência natural da livre iniciativa que era conferida aos agentes econômicos. Segundo o modelo liberal clássico, a simples conjugação dos interesses individuais era o suficiente para garantir o bem-estar social e o desenvolvimento econômico.

A estrutura do mercado à época contribuía para essa conclusão. Logo após o ressurgimento do comércio, a estrutura dos mercados de bens e de serviços era bastante atomizada, inexistindo, por parte dos agentes econômicos, qualquer poder de influenciar preços ou condições de venda (o que configura o poder de mercado). A participação de mercado dos agentes econômicos era insuficiente para qualquer investida nesse sentido. Em geral, os mercados eram competitivos. Não havia, portanto, razão para que o Estado interviesse para preservar um ambiente concorrencial saudável.

Essa situação estrutural começou a se alterar a partir da revolução industrial. A substituição da mão de obra braçal pelo sistema fabril e o aperfeiçoamento das técnicas de distribuição permitiram uma maior concentração nos mercados relevantes. Diminuiu-se o número de agentes econômicos, com a conseqüente formação de grandes empresas, por meio de operações societárias (fusões ou aquisições) ou de crescimento próprio, alterando a estrutura do mercado (de vários agentes os mercados relevantes passaram a ser caracterizados por oligopólios e monopólios).

Dotados de altas participações de mercado (e em razão de determinadas características de mercado), alguns agentes passaram a concentrar capital, por serem capazes de manipular as variáveis de preço e quantidade, com o objetivo de aumentar lucros. Esse novo contexto gerou pressões populares com o objetivo de diminuir o poder que as grandes companhias passaram a ter depois desse 
processo de concentração. $\mathrm{O}$ resultado imediato das pressões foi a promulgação de leis de defesa da concorrência, primeiro no Canadá e, logo após, nos Estados Unidos. Em momentos posteriores, diversos países adotaram legislações de defesa da concorrência, entre eles o Brasil.

\subsection{Dos Limites à Livre Iniciativa}

As legislações de defesa da concorrência que surgiram no final do século XIX tinham expressa preocupação com o crescente número de oligopólios e monopólios e, conseqüentemente, com os efetivos e potenciais abusos desses agentes econômicos possuidores de poder de mercado. Tais diplomas refletiam justamente o interesse em manter a liberdade e a igualdade nos mercados de bens e serviços.

É importante dizer, no entanto, que a regra geral continuava (e continua) a ser a da livre iniciativa. Mas, nascia a partir dali a noção de que a livre iniciativa teria limites em razão da percepção de que preços e quantidade, além de outras condições mercadológicas, poderiam ser alterados de modo artificial (e, portanto, prejudicial) por agentes dotados de grande poder de mercado. $\mathrm{O}$ bem-estar social poderia ser prejudicado se não houvesse qualquer intervenção por parte do Estado.

Não se confundem, dessa forma, a livre iniciativa e a livre concorrência. Como se pode inferir intuitivamente, nem todas as formas de competição são lícitas e, portanto, benéficas à concorrência. Isso torna necessário que o Estado atue de modo a preservar o ambiente concorrencial saudável, impedindo e coibindo a prática de condutas anticompetitivas, por agentes econômicos, que sejam deletérias ao consumidor e à sociedade como um todo.

As liberdades não são absolutas. Conseqüentemente, essa máxima também se aplica ao princípio da livre iniciativa ${ }^{2}$. Assim, o princípio da livre concorrência fornece a base jurídica para impedir que os agentes econômicos possam desvirtuar as prerrogativas de liberdade de iniciativa, prejudicando a sociedade e os mercados. A manutenção e a preservação da liberdade e da igualdade dependem da atuação do Estado na economia limitando a livre iniciativa de agentes econômicos. E isso se dá, como dito, com fundamento no princípio da livre concorrência.

${ }^{2}$ Logicamente, a livre concorrência não é o único limite imposto à livre iniciativa. Outras restrições à livre iniciativa têm sido admitidas pelo Poder Judiciário. É o caso da Lei n. 8.039/90, que estabelecia critérios para o reajuste de mensalidades escolares. Essa lei, que impunha limites à livre iniciativa, ao limitar a possibilidade de as escolas fixarem livremente seus preços, foi considerada constitucional pelo Supremo Tribunal Federal no julgamento da ADIN 319. 
Em resumo, as transformações socioeconômicas (que ocorreram impulsionadas pelo processo de industrialização) provocaram uma transformação na estrutura que justificava, ao menos em parte, os entendimentos liberais a respeito da livre concorrência. Como efeito, a política do laissez-faire foi destronada, ganhando importância o processo de socialização do Direito. Nesse novo cenário, o Estado intervém na economia com o propósito de garantir que os direitos subjetivos atinjam sua função social. Daí o papel do princípio da livre concorrência como uma baliza da livre iniciativa.

Após a breve e genérica descrição histórica da livre concorrência, resta analisar como o princípio foi introduzido no ordenamento jurídico brasileiro, examinando, para tanto, a evolução dos dispositivos pertinentes no país, o que se fará a seguir.

\section{EVOLUÇÃO HISTÓRICA DA LIVRE CONCORRÊNCIA NO BRASIL}

\subsection{A Intervenção do Estado na Economia: Regras contra o Abuso de Poder de Mercado}

As Constituições Federais de 1824 e de 1891 não foram textos que se caracterizaram por dispor sobre regras de intervenção no mercado. E a razão para isso era simples. Ambos os textos foram inspirados em pensamentos extremamente liberais, não legitimando um papel maior do Estado na economia.

Essa orientação começou a se alterar paulatinamente a partir da Constituição de 1934³ . Inspirada na Constituição de Weimar (1919) e na Constituição Mexicana (1917), a Constituição de 1934 introduziu regras sobre a organização econômica pelo Estado, atribuindo a ele a função de mero garantidor da liberdade de mercado, ressalvando, no entanto, determinados limites (estabelecidos de modo a proporcionar a existência digna de todos os cidadãos, o que seria atingida por meio da observância aos princípios da justiça e às necessidades da vida nacional).

A Constituição de 1937 também exaltava a liberdade de iniciativa, desta vez condicionando-a à presença de intervenção estatal para suprir deficiências da iniciativa individual e para coordenar fatores de produção, de sorte a fazer prevalecer os interesses da nação. Essa Constituição previa dispositivo dispondo sobre crimes contra a economia popular (Artigo 141).

${ }^{1}$ A proteção à livre concorrência nasceu, no âmbito constitucional, em dispositivos que visavam a proteger a economia popular (Artigos 115 e 117 da CF de 1934 e 141 da CF de 1937). A tipificação de crimes contra a economia popular evidentemente se referia à proteção contra abusos de poder econômico. Em momentos posteriores, e especialmente na CF de 1988, os termos livre iniciativa e livre concorrência ganharam papel de destaque. 
O Artigo 141 da Constituição de 1937 foi regulamentado pelo Decreto n. 869 de 1938, uma norma de caráter penal-econômico, que visava a reprimir o abuso do poder econômico. Normas que proibiam condutas anticompetitivas que até hoje perduram nos textos legislativos em vigor (como fixação de preços entre concorrentes e venda de produtos abaixo do preço de custo) foram introduzidas no ordenamento brasileiro por meio daquele decreto, que pouca ou nenhuma aplicabilidade teve.

Em 1945, após a apresentação do projeto de autoria do Ministro Agamemnon Magalhães, foi promulgado o Decreto-Lei n. 7.666 (que foi apelidada de "Lei Malaia”, em virtude do seu caráter rigoroso). A grande novidade implementada por esse diploma legal foi a criação do primeiro órgão de defesa da concorrência, que se chamava Comissão Administrativa de Defesa Econômica (CADE). Logo após a queda de Getúlio Vargas, o Decreto-Lei foi revogado, não tendo sequer completado três meses de vigência.

Sob a égide da Constituição de 1946, foi promulgada a "primeira" Lei de Defesa da Concorrência Brasileira, a Lei n. 4.137, cujo projeto, também de Agamemnon Magalhães, se arrastou desde 1948 nas casas do Congresso Nacional, tendo sido aprovado somente em 1962. Essa lei regulamentava o Artigo 148 da carta de 1946, que previa a necessidade de repressão de qualquer forma de abuso de poder econômico, que tenha por fim dominar mercados, eliminar a concorrência e aumentar arbitrariamente lucros.

A Lei n. 4.137 de 1962 criou o Conselho Administrativo de Defesa Econômica (CADE), com a finalidade de implementar o primeiro tribunal de defesa da concorrência no país. A exemplo das disposições normativas anteriores, esse diploma legal não teve grande aplicabilidade. Logo após a sua promulgação, o Brasil entrou num longo período de ditadura militar, que inaugurou uma política de intervencionismo extremado, envolvendo controle de preços e substituição de importações. Durante esse período vigoraram as Constituições de 1967 e 1969, que enfatizavam a segurança do Estado.

A política de intervenção estatal gerou um modelo econômico em que não havia concorrência e, portanto, não havia maior sentido em se ter um sistema de defesa da concorrência, quiçá um sistema efetivo. Além dessa questão (que representava uma opção política do governo à época), freqüentemente as decisões proferidas pelo CADE eram questionadas no Poder Judiciário, que as revertia, tornando a competência daquele órgão inócua, ao impedir a aplicação de multas e sanções aos agentes econômicos condenados.

Em razão disso, durante um longo período, o CADE foi um órgão de utilidade questionável, cujas decisões, em grande parte, experimentavam eficácia meramente 
formal, situação essa que somente veio a se modificar quando do processo de redemocratização do país, que resultou na promulgação da Constituição de 1988. A partir do momento em que o Estado reduziu o seu poder de intervenção na economia, assumindo, em contrapartida, funções de incentivo, planejamento e fiscalização, a política de defesa da concorrência voltou a ter importância no cenário econômico brasileiro.

\subsection{A Constituição Econômica}

A Constituição de 1988 estabeleceu, como fundamentos da ordem econômica, a valorização do trabalho humano e a livre iniciativa (Artigo 170, caput). Houve expressa preocupação em colocar o Estado como ente subsidiário, deixando que os agentes de mercado tivessem a regência da economia nacional. Nesse sentido, também foi a livre iniciativa considerada como fundamento da república (Artigo $1^{\underline{a}}$, inciso IV), ao lado da soberania, da cidadania, da dignidade da pessoa humana e do pluralismo político.

Eminentemente, portanto, o modelo econômico escolhido pela Constituição de 1988 se baseava na atividade de agentes econômicos particulares e não no estado, abandonando a posição intervencionista que caracterizava o período da ditadura militar. À economia de mercado recaiu a tarefa primordial de promover o desenvolvimento sócio-econômico, bem como o bem-estar social.

Como a livre iniciativa, na qualidade de fundamento da ordem econômica, é um instrumento que deve levar em consideração a finalidade de garantir a todos existência digna, conforme os ditames da justiça social, com esse propósito a Constituição de 1988 houve por bem determinar a observância a alguns princípios, entre os quais se destacam, para o assunto ora tratado, o princípio da livre concorrência (Artigo 170, inciso IV) e o princípio de defesa do consumidor (Artigo 170, inciso V).

E a Constituição de 1988 assim o fez por uma razão. O propósito explícito da previsão constitucional a esse respeito era o de afastar a interpretação liberal clássica no sentido de que a livre iniciativa seria absoluta e que, em conseqüência, dela decorreria a livre concorrência. Reconheceu a Constituição que, de fato, há a possibilidade de distorções no mercado causadas em função do poder econômico de determinados agentes de mercado. E, por conta disso, deixou claro que a presença do Estado (na sua vertente fiscalizadora) assegura a liberdade dos e entre os agentes econômicos.

Segundo a Constituição Federal brasileira em vigor, o princípio da livre concorrência é um dos balizadores necessários para que a livre iniciativa possa 
corretamente atender à sua função social. É importante ressaltar que, em termos gerais, não é difícil definir o escopo da livre concorrência. Esse princípio impõe obrigações positivas e negativas aos agentes econômicos. Se de um lado permite a adoção de quaisquer técnicas lícitas de conquista de mercado - para o que conta com a neutralidade do Estado - de outro proíbe (e pune, se for o caso) a utilização de meios que falseiem a livre competição.

Aliás, as provisões constitucionais que encerram a obrigação de proteger a livre concorrência não se limitam ao inciso IV do Artigo 170 da Constituição. No parágrafo $4^{a}$ do Artigo 173, a Constituição prevê lei que terá por função "reprimir o abuso do poder econômico, que vise à dominação dos mercados, à eliminação da concorrência e ao aumento arbitrário de lucros”. Esse dispositivo, aliás, nada mais é do que, grosso modo, uma repetição de outros análogos previstos em constituições passadas, o que leva a crer que a Constituição atual deu um passo a mais, ao dispor especificamente sobre o princípio da livre concorrência e a sua relação com a livre iniciativa, fundamento da ordem econômica nacional.

\subsection{A Lei de Defesa da Concorrência (Lei n. 8.884/94)}

Logo após a promulgação da Constituição de $1988^{4}$, surgiram duas leis em complementação à Lei n. 4.137/62 (Leis n. 8.002/90 e n. 8.158/91), tendo curto período de vigência. Essas leis (assim como a própria Lei n. 4.137/62) foram revogadas pela Lei n. 8.884/94, a nova lei de defesa da concorrência, promulgada em consonância com os novos preceitos de ordem econômica previstos na Constituição de 1988.

A Lei n. 8.884/94 prevê expressamente, em seu Artigo $1^{\circ}$, que se orienta pelos ditames constitucionais de liberdade de iniciativa, livre concorrência, função social da propriedade, defesa dos consumidores e repressão ao abuso do poder econômico. Esse artigo, por si só, reforça o argumento de que nova ordem constitucional pretende uma proteção à concorrência mais ampla do que a simples repressão aos abusos econômicos.

Mas uma das maiores inovações implementadas pela nova Lei de Defesa da

\footnotetext{
${ }^{4}$ Também em matéria de defesa da concorrência, foi promulgada a Lei n. 8.137/90, que define crimes contra a ordem tributária, econômica e contra as relações de consumo. Essa lei tipifica como crime diversas práticas deletérias à concorrência, como, por exemplo, o abuso do poder de mercado mediante a fixação artificial de preços ou quantidades por concorrentes (cartel), discriminação de preços, venda de mercadorias abaixo do preço de custo com o objetivo de impedir a concorrência (preços predatórios), entre outras.
} 
Concorrência foi a transformação do CADE em autarquia federal vinculada, de modo indireto, ao Ministério da Justiça. Essa medida teve o propósito de conferir àquele órgão a autonomia e independência necessária ao cumprimento de suas funções. Além disso, a nova lei aumentou a composição do plenário do CADE (que anteriormente contava com quatro conselheiros), para seis conselheiros.

De modo a operacionalizar a defesa da concorrência, a Lei n. 8.884 dividiu as suas funções em vertentes preventiva e repressiva. A vertente preventiva diz respeito ao controle, por parte dos órgãos de defesa da concorrência, de operações de grande porte (fusões e aquisições, entre outras), denominadas atos de concentração econômica, que podem ter impacto na concorrência. Os Artigos 54 e seguintes da lei regulam o procedimento de submissão dos atos de concentração para análise dos órgãos de defesa da concorrência brasileiros. Como medidas de controle estrutural, os órgãos podem aprovar, impor restrições ou mesmo determinar a desconstituição da operação, caso ela seja irremediavelmente lesiva à concorrência.

Já a vertente repressiva se refere à punição das práticas anticompetitivas. A Lei n. 8.884/94 condiciona a ilicitude dessas condutas à produção, efetiva ou potencial, de danos à concorrência. As práticas anticompetitivas foram tipificadas exemplificativamente no Artigo 21 (cartéis, preços predatórios, venda casada, entre outros), ao passo que os efeitos foram listados no Artigo 20 daquele diploma legal. Os efeitos previstos no dispositivo são: (i) limitar, falsear ou de qualquer forma prejudicar a livre concorrência ou a livre iniciativa; (ii) dominar mercado relevante de bens ou serviços; (iii) aumentar arbitrariamente os lucros. O quarto efeito previsto no Artigo 20 (exercer de forma abusiva posição dominante) é um gênero do qual os efeitos anteriormente mencionados são espécies.

Os responsáveis por práticas anticompetitivas são sujeitos a penas de natureza pecuniária e não pecuniária. Entre as primeiras, vale ressaltar que a multa imposta em caso de condenação por prática anticompetitiva, no caso de empresa ${ }^{5}$, varia entre um a trinta por cento do valor do faturamento bruto do seu último exercício, excluídos os impostos (Artigo 23, inciso I). Destaca-se que esse valor não poderá ser inferior à vantagem auferida pela empresa na conduta anticompetitiva, quando quantificável, o que revela a intenção do diploma de defesa da concorrência em desestimular novas práticas lesivas à concorrência.

Entre as penas de caráter não pecuniário (que podem ser aplicadas sem prejuízo das multas), os órgãos de defesa da concorrência poderão proibir a companhia

\footnotetext{
${ }^{5}$ Administradores de empresas que foram condenadas por práticas anticompetitivas são igualmente sujeitos à multa. Nesse caso, a pena pecuniária varia entre dez a cinqüenta por cento do valor da multa aplicável à empresa (Artigo 23, inciso II).
} 
condenada de contratar com instituições financeiras oficiais e de participar em licitação de serviços públicos em prazo não inferior a cinco anos, além de da inscrição do infrator no Cadastro Nacional de Defesa do Consumidor, entre outros. Também em virtude de condenação por práticas anticoncorrenciais, poderão ser aplicadas sanções estruturais, tais como a determinação de cisão de sociedade, transferência de controle societário, venda de ativos e até mesmo cessação parcial de atividades.

\section{COMENTÁRIOS FINAIS SOBRE O PRINCÍPIO DA LIVRE CONCORRÊNCIA}

A livre concorrência ainda não é um valor que foi integrado à cultura brasileira. O longo período de controle de preços, em razão de política implementada no período da ditadura militar, gerou a perspectiva de que a figura de um Estado intervencionista, fixando condições de mercado, seria a melhor solução para maximizar o bem-estar social.

Maior inverdade não há. As vantagens do modelo concorrencial demoram a ser percebidas pela sociedade, o que provoca uma certa descrença com relação à opção por uma economia de mercado. Mas o fato é que, salvo algumas exceções (em que o Estado deve intervir para evitar distorções de mercado ${ }^{6}$ ), os benefícios decorrentes de um modelo econômico baseado na livre iniciativa, com a garantia de livre concorrência, superam (em muito) a situação de bem-estar provocada por um modelo que prima pela intervenção estatal. Tal questão foi amplamente explorada no decorrer deste articulado.

Ciente disso, a Constituição de 1988 adotou a economia de mercado como regra. E expressamente condicionou a liberdade de iniciativa à observância ao princípio da livre concorrência, a grande salvaguarda da igualdade de competição entre os agentes econômicos. Garantiu assim a atenção à justiça social, possibilitando a criação, em matéria infraconstitucional, dos elementos capazes de assegurar a ampla fiscalização, por parte do Estado, visando à manutenção de um ambiente concorrencial saudável, tarefa primordialmente atribuída aos órgãos governamentais de defesa da concorrência.

\footnotetext{
${ }^{6}$ Seja por falhas de mercado, ou em razão de essencialidade do serviço, o que legitima uma maior intervenção do Estado sobre atividade. Isso ocorre em diversos mercados, tais como energia, telecomunicações, saneamento, entre outros.
} 


\section{REFERÊNCIAS}

BASTOS, Celso Ribeiro. O Princípio da Livre Concorrência na Constituição Federal. Cadernos de Direito Tributário e Finanças Públicas, São Paulo, v. 3, n. 10, p. 190-204, 1995.

BLASSELLE, Richard. Traité de Droit Européen de la Concurrence. Paris: Publisud, 2002.

COMPARATO, Fábio Konder. O indispensável Direito Econômico. Revista dos Tribunais, São Paulo, n. 353, p. 14-26, mar. 1965.

COSTA, Marcos da; MENEZES, Paulo Lucena de; MARTINS, Rogério Gandra da Silva (Coord.). Direito concorrencial aspectos jurídicos e econômicos: Comentários à Lei $n^{\underline{a}}$ 8.884/94 e Estudos Doutrinários. Rio de Janeiro: América Jurídica, 2003.

COSTA, Maurício de Moura. O Princípio Constitucional da Livre Concorrência. Revista do Ibrac, São Paulo, v. 5, n. 1, p 7-26, 1998.

FERRAZ JÚNIOR, Tércio Sampaio. Abuso de Poder Econômico por Prática de Licitude Duvidosa Amparada Judicialmente. Revista de Direito Público da Economia, Brasília, n.1, 215-25, jan./mar. 2003.

. Lei de Defesa da Concorrência. Arquivos do Ministério da Justiça, nova fase, v. 45, n. 180, p. 175-185, jul./dez. 1992.

FERREIRA, Maria Conceição Martins. Princípios Constitucionais Informadores da República Federativa do Brasil e da Ordem Econômica (Soberania, Livre Iniciativa e Valor Social do Trabalho). Cadernos de Direito Constitucional e Ciência Política, São Paulo, v. 6, n. 25, p. 134-68, out./dez. 1998.

GATTO, Ana Carolina dos Santos. A Defesa da Livre Concorrência e a Proteção do Consumidor. Revista do Ibrac, São Paulo, v. 9, n. 1, p. 257-81, 2002.

GOYDER, Daniel George EC Competition Law. $4^{\text {th }}$ ed. New York: Oxford University Press, 2003.

GRAU, Eros Roberto. Princípio da livre concorrência: função regulamentar e função normativa. Revista Trimestral de Direito Público, São Paulo, n. 4, p. 10429, 1993.

A Ordem Econômica na Constituição de 1988. 8. ed. São Paulo: Malheiros, 2003. 
MELLO, Celso Antônio Bandeira. de. Desvio de poder em ato legislativo: ofensa ao princípio da livre concorrência, ao da defesa do consumidor e ao da igualdade. Boletim de Direito Administrativo, São Paulo, v. 14, n. 10, p. 613-6, out. 1998. NUSDEO, Fábio. Curso de economia: introdução ao Direito Econômico. 2. ed. São Paulo: Editora Revista dos Tribunais, 2000.

SILVEIRA, Paulo Antônio Caliendo V. da. Aspectos Gerais da Proteção da Concorrência no Mercosul. Revista de Direito Tributário, São Paulo, n. 83, p. 143-83, 2000.

TAVARES, André Ramos. Direito Constitucional Econômico. São Paulo: Método, 2003.

XOUDIS, Julia. Les accords de distribution au regard du droit de la concurrence. Genebra: Schulthess, 2002. 